\title{
Recurrent genetic alterations in hepatitis C-associated hepatocellular carcinoma detected by genomic microarray: a genetic, clinical and pathological correlation study
}

Yajuan J Liu*, Yang Zhou and Matthew M Yeh

\begin{abstract}
Background: In the US, approximately $50 \%$ of hepatocellular carcinoma (HCC) is caused by hepatitis-C virus (HCV) infection. The molecular mechanism of a malignant transformation of hepatocyte induced by HCV infection is still largely unclear. There are several clinical and pathological staging systems for HCC, but none of them include biological parameters as predictors for prognosis and there has not been a standardized molecular classification of HCC. To understand the underlying pathogenic genetic alterations in HCV-associated HCC and aid in molecular classification of HCC and patient prognosis, microarray analysis of DNA copy number alterations in HCC were conducted using whole genome microarray with DNA from formalin-fixed paraffin-embedded (FFPE) specimens of both cancer tissues and paired nearby cirrhotic non-neoplastic tissues.
\end{abstract}

Results: Our results show that the most common chromosomal aberrations ( $>5 \mathrm{Mb}$ ) observed in HCC were chromosomal gains of 1q (80\%), 8q (60\%), 7q (40\%), 5p (33\%), 7p (33\%), Xq (33\%), 5q (27\%), and Xp (20\%), as well as chromosome losses of 17p (40\%), 4q21.21-q26 (33\%), 8p (33\%), 1p36.11-pter (20\%), and 9p (20\%). Statistically significant smaller copy number alterations ( $3.9 \mathrm{~kb}$ to $644 \mathrm{~kb}$ ) were identified using STAC algorithm, including losses of FGFR3, RECQL4, NOTCH1, PTEN, TSC2, and/or ASPSCR1 and gains of ETV1and/or MAF. Correlation analysis between genetic data and pathological data showed that gain of 1q21.1-q23.2 and gain of 8q11.1q13.1 are significantly associated with grade 2-4 and moderately or poorly differentiated HCCs, and gain of chromosome $5 q$ was significantly associated with HCCs with vascular invasion, while gain of chromosome $7 q$ is significantly associated with stage I HCCs.

Conclusions: This study has provided a detailed map of genomic aberrations occurring in HCV-associated HCC and has suggested candidate genes. In addition, gene enrichment analysis on the recurrent abnormal regions indicated NF- kappaB and BMP signaling pathways in HCC development and progression. This study demonstrated that genomic microarray test can be used to distinguish HCC from non- neoplastic cirrhotic nodules and to identify prognostic factors associated with HCC progression using pathologically characterized FFPE samples. Our data support the utility of genomic microarray test for the diagnosis, risk stratification, and pathogenic studies of HCC.

Keywords: Hepatocellular carcinoma, Hepatitis-C virus, Copy number aberration, Copy number variants, Genomic microarray, Prognosis, Pathological correlation

\footnotetext{
*Correspondence: yajuan@uw.edu

Department of Pathology, University of Washington, 1959 NE Pacific Street, Box 357470, Seattle, WA 98195, USA
}

\section{Biomed Central}

(c) 2014 Liu et al.; licensee BioMed Central Ltd. This is an Open Access article distributed under the terms of the Creative Commons Attribution License (http://creativecommons.org/licenses/by/4.0), which permits unrestricted use, distribution, and reproduction in any medium, provided the original work is properly credited. The Creative Commons Public Domain Dedication waiver (http://creativecommons.org/publicdomain/zero/1.0/) applies to the data made available in this article unless otherwise stated. 


\section{Background}

Hepatocellular carcinoma ( $\mathrm{HCC}$ ) is one of the most common malignant neoplasm and represents the third leading cause of cancer-related death worldwide $[1,2]$. The incidence of $\mathrm{HCC}$ is increasing in the United States and Europe, mostly because of the high prevalence of hepatitis $\mathrm{C}$ virus (HCV) infection $[3,4]$. The molecular mechanism of a malignant transformation of hepatocyte induced by HCV infection is still largely unclear. The lack of good cellular and animal models of HCV hepatocarcinogenesis further hampers the understanding of the underlying mechanisms. Given that $\mathrm{HCV}$ is an RNA virus which replicates in the cytoplasm and has little potential for integration of its genome into host DNA [5,6], liver cirrhosis has generally been considered a prerequisite for $\mathrm{HCV}$-infected livers to develop HCC. The pathogenesis of $\mathrm{HCC}$ in chronic HCV infection is generally accepted as chronic inflammation and injury, which leads to fibrosis with eventual progression to cirrhosis and subsequent development of HCC [7]. There are several clinical and pathological staging systems for HCC, but none of them include biological parameters as predictors for prognosis [8], and there has not been a standardized molecular classification of HCC. The low efficacy of systemic chemotherapies for $\mathrm{HCC}(<40 \%)$ [7] encourage intensive investigation to identify the molecular mechanisms implicated in the carcinogenesis of HCV associated HCC, an area of great need.

This study aimed to determine the patterns of recurrent genetic alterations and common pathways involved in the development and progression of $\mathrm{HCV}$-associated $\mathrm{HCC}$ using high resolution genomic microarray analysis and the correlations of genetic alterations with tumor phenotype, clinical presentation and outcome to improve the identification of risk factors in molecular HCC subtypes. Although genomic studies for characterization of DNA copy number alterations of $\mathrm{HCV}$-associated HCC $[9,10]$ or HCC due to various or unspecified etiologies [11-14] have been conducted, these studies used either conventional comparative genome hybridization $(\mathrm{CGH})$ on metaphase cells or low density Bacterial Artificial Chromosome (BAC) clone array-based CGH analysis, therefore, submicroscopic and small copy number alterations could be undetected. In addition, no correlation analysis between genetic alterations and clinical and pathological data of HCC was conducted to define clinically relevant subtypes for prognosis. Furthermore, all the specimens used in this study were formalin-fixed paraffin-embedded (FFPE) HCC tissues, demonstrating the feasibility of whole genome microarray analysis using FFPE HCC specimens, and paired non-neoplastic cirrhotic nodules were also examined for comparison.

\section{Results}

\section{Clinical and pathologic characterizations of HCC specimens}

A total of 15 cases from which the paraffin blocks contained enough tumors for DNA isolation were included. The patients' demographics, clinical and pathologic features of the specimens are summarized in Table 1 . The age of these patients ranged from 45 to 67 years with an average of 56 years. The tumor size ranged from 1 to $4 \mathrm{~cm}$ with an average of $2.2 \mathrm{~cm}$. Pathological examinations of the background livers in the explanted specimens showed

Table 1 Summary of the patient demographics, clinical and pathologic features of the HCC specimens

\begin{tabular}{|c|c|c|c|c|c|c|c|c|c|c|c|}
\hline $\begin{array}{l}\mathrm{HCC} \\
\text { specimens }\end{array}$ & Age & Gender & Ethnicity & Etiology & $\begin{array}{l}\text { HCV } \\
\text { genotype }\end{array}$ & $\begin{array}{l}\text { Cirrhotic } \\
\text { liver }\end{array}$ & Grade & $\begin{array}{l}\text { Tumor } \\
\text { differentiation }\end{array}$ & $\begin{array}{l}\text { Tumor } \\
\text { stage (TNM) }\end{array}$ & $\begin{array}{l}\text { Tumor } \\
\text { size }(\mathrm{cm})\end{array}$ & $\begin{array}{l}\text { Vascular } \\
\text { invasion }\end{array}$ \\
\hline HCC01 & 45 & $\mathrm{~m}$ & caucasian & $\mathrm{HCV}$ & na* & yes & G2 & moderate & T1NxMx & 1.3 & no \\
\hline $\mathrm{HCCO} 2$ & 57 & $\mathrm{~m}$ & Asian & $\mathrm{HCV}$ & na & yes & G4 & poor & T1NxMx & 2.7 & no \\
\hline HCCO3 & 57 & $\mathrm{~m}$ & caucasian & $\mathrm{HCV}$ & na & yes & G2 & moderate & $\mathrm{T} 1 \mathrm{~N} \times \mathrm{Mx}$ & 2 & no \\
\hline $\mathrm{HCCO} 4$ & 49 & $\mathrm{~m}$ & unknown & $\mathrm{HCV}$ & na & yes & G4 & poor & T3NxMx & 3 & yes \\
\hline HCC05 & 65 & $\mathrm{~m}$ & unknown & $\mathrm{HCV}$ & $2 a$ & yes & G3 & moderate & T2NOMx & 2.4 & no \\
\hline HCCO6 & 50 & $\mathrm{~m}$ & caucasian & $\mathrm{HCV}$ & na & yes & G3 & moderate & T2N0Mx & 2.5 & yes \\
\hline HCCO7 & 56 & $\mathrm{~m}$ & caucasian & $\mathrm{HCV}$ & $2 b$ & yes & G1 & well & T1N0Mx & 1.5 & no \\
\hline HCC08 & 62 & $\mathrm{~m}$ & caucasian & $\mathrm{HCV}$ & na & yes & G2 & moderate & $\mathrm{T} 2 \mathrm{~N} \times \mathrm{Mx}$ & 2.1 & no \\
\hline HCCO9 & 51 & $\mathrm{~m}$ & caucasian & $\mathrm{HCV}$ & $1 a$ & yes & G1 & well & T1NxMx & 1.8 & no \\
\hline $\mathrm{HCC} 10$ & 60 & $\mathrm{~m}$ & caucasian & $\mathrm{HCV}$ & 3 & yes & G3 & moderate & T1NxMx & 1.7 & yes \\
\hline HCC11 & 53 & $\mathrm{~m}$ & caucasian & $\mathrm{HCV}$ & na & yes & G3 & moderate & $\mathrm{T} 2 \mathrm{~N} \times \mathrm{Mx}$ & 3 & no \\
\hline $\mathrm{HCC} 12$ & 57 & $\mathrm{~m}$ & unknown & $\mathrm{HCV}$ & na & yes & G1 & well & T1N0Mx & 2.3 & yes \\
\hline $\mathrm{HCC} 13$ & 48 & $\mathrm{~m}$ & Asian & $\mathrm{HCV}$ & na & yes & $\mathrm{G} 2$ & moderate & $\mathrm{T} 1 \mathrm{~N} \times \mathrm{Mx}$ & 1 & no \\
\hline $\mathrm{HCC} 14$ & 66 & $\mathrm{~m}$ & Native American & $\mathrm{HCV}$ & na & yes & G1 & well & $\mathrm{T} 1 \mathrm{~N} \times \mathrm{Mx}$ & 3 & no \\
\hline $\mathrm{HCC} 15$ & 51 & $\mathrm{~m}$ & caucasian & $\mathrm{HCV}$ & $1 a$ & yes & G1 & well & T1NxMx & 1.5 & no \\
\hline
\end{tabular}

*na - not available. 
that all the cases had cirrhosis. All 15 cases were negative for hepatitis B co-infection by serology or viral DNA test, and occult hepatitis B was also excluded by PCR. Due to the retrospective nature of the study, only a subset of these specimens has HCV genotype data.

Whole genome microarray analysis using FFPE specimens DNA was extracted from FFPE tissues of 16 HCCs and 10 paired non-neoplastic cirrhotic liver tissues. Except for one HCC specimen, microarray analysis for copy number changes were successful for 15 HCC specimens and 10 paired non-neoplastic cirrhotic liver tissues, giving a 96.2\% successful rate for microarray analysis using FFPE specimens. As an example, HCC01 showed a copy gain of the long arm of chromosome 1 (1q) (Table 1, Figure $1 \mathrm{~A}$, ) and amplified regions containing multiple genes on 1q (Figure 1B). Tumor cellularity, the relative proportion of tumor and normal cells in a sample, affects the sensitivity of copy number detection, and can be estimated based on the review of $\mathrm{H} \& \mathrm{E}$ stained slide by the pathologist. In addition, the $\log 2$ ratio and copy number line fit plots by Cytogenomics can also be used to indicate clonal diversity and estimate tumor cellularity for each clone. For instance, the tumor cellularity in HCC01 was estimated to be approximately 57\% based on the pathologist's review of the $H$ \& E stained slide and the $\log 2$ ratio and copy number line fit plot by Cytogenomics. In addition, no clonal diversity in $\mathrm{HCCO} 1$ was indicated by the log 2 ratio and copy number line fit plot.
Based on the values of $\log 2$ ratios and $57 \%$ tumor cellularity, the numbers of copy gains in the amplified regions on 1q of HCC01 were estimated to be four and seven copies (including gains of $M D M 4$ and $P I K 3 C 2 B$ ), respectively (Figure 1B).

\section{Recurrent copy number alterations in HCC}

Clonal chromosomal abnormalities were detected in all HCC samples but not in their paired non-neoplastic tissues. Accumulative and individual chromosomal imbalances in the HCV-HCC genomes are summarized in Figure 2. Recurrent copy gains and losses of genomic regions that were larger than $5 \mathrm{Mb}$ in the HCV-HCC specimens were summarized in Table 2. The common chromosomal aberrations (>5 Mb) observed in HCC were chromosomal gains of $1 \mathrm{q}(80 \%), 8 \mathrm{q}(60 \%), 7 \mathrm{q}$ (40\%), 5p (33\%), 7p (33\%), Xq (33\%), 5q (27\%), and Xp (20\%), as well as chromosome losses of $17 \mathrm{p}(40 \%)$, 4q21.21-q26 (33\%), 8p (33\%), 1p36.11-pter (20\%), and 9p (20\%). The numbers of chromosomal imbalance larger than $5 \mathrm{Mb}$ in each case ranged from 2 to 12 copy number changes per case with 7 copy number changes per case on average. No chromosomal aberrations were observed in the 10 paired non-neoplastic cirrhotic liver tissues that were available for examination.

Statistically significant smaller copy number alterations were identified and ranged from $3.9 \mathrm{~kb}$ to $644 \mathrm{~kb}$ using STAC algorithm implemented in Nexus 7.5 (Table 3). Among the genes in these regions, known cancer genes

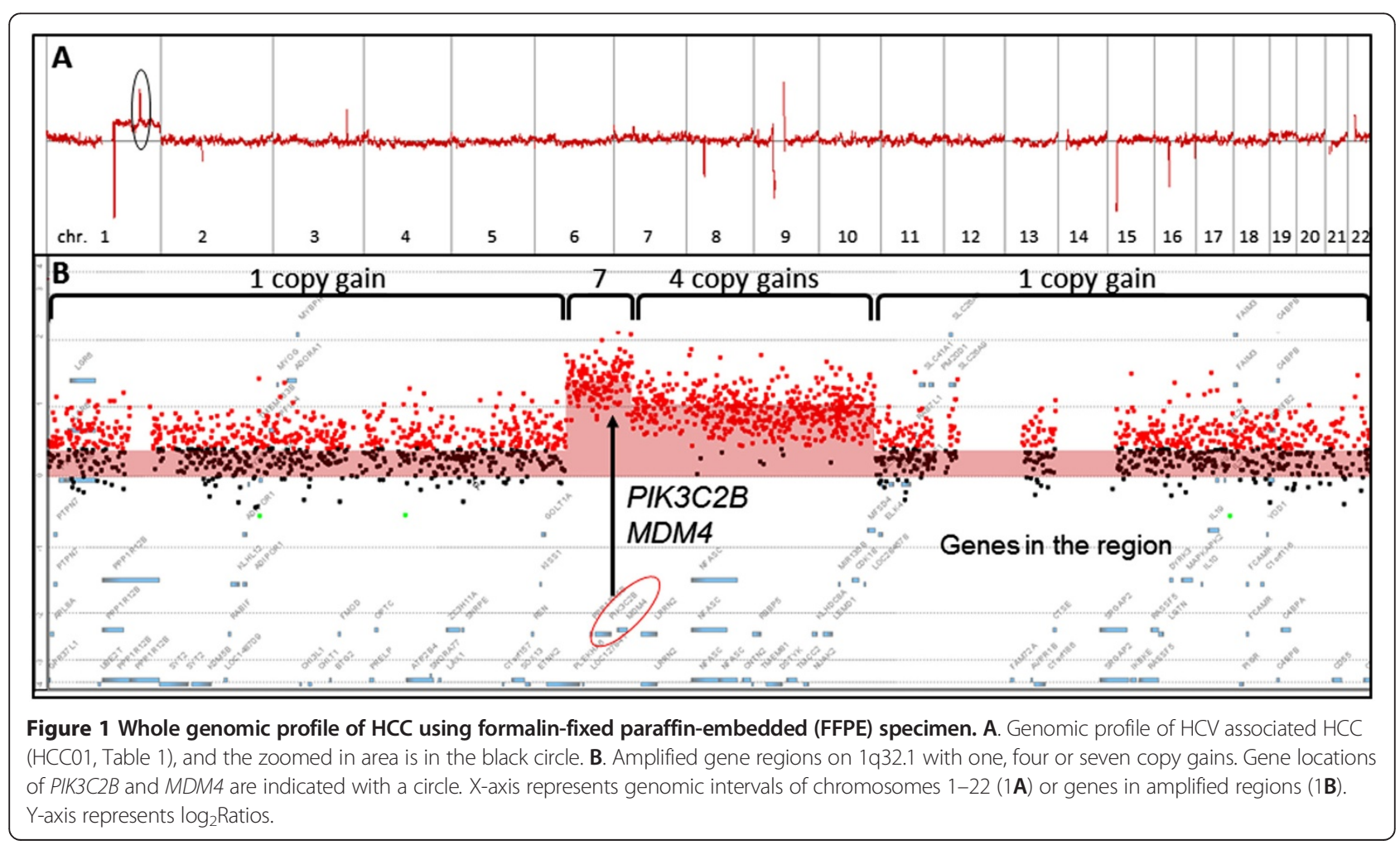




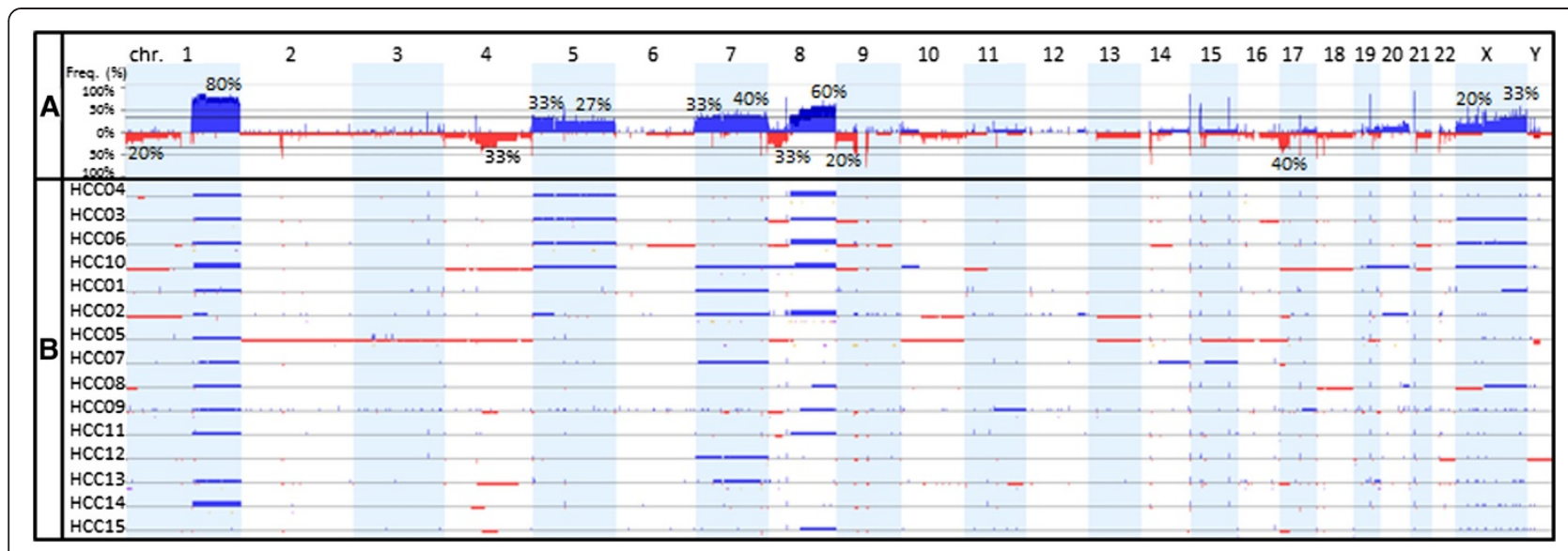

Figure 2 Genomic profile of HCC specimens showing recurrent chromosomal gains and losses. A. The accumulative frequency (or aggregate) plot for the HCC specimens with rate (\%) labeled for the most frequent recurrent clonal chromosomal gains and losses in 15 HCV-associated HCC specimens. Blue bars indicate gains and red bars indicate losses. B. Genomic profiles of copy number alterations in individual HCC specimens.

based on the Sanger Census cancer gene list (http:// cancer.sanger.ac.uk/cancergenome/projects/census/) included losses of FGFR3, RECQL4, NOTCH1, PTEN, TSC2, and/or ASPSCR1 and gains of ETV1 and/or MAF. In addition, copy gain involving Androgen receptor $(A R)$ were observed in five of 15 HCCs analyzed.

\section{Correlation of recurrent genetic alterations with clinical and pathologic data}

Three comparison/correlation analyses were conducted and the difference in frequency for gains and losses in each group are shown in Figure 3 and significant genomic aberrations identified are summarized in Tables 4, 5 and 6. A subset of signature copy number alterations associated with specific HCC pathologic features was identified.

In comparison analysis I, five grade 1 and well differentiated HCCs (A, Figure 3) were compared with ten grade 2-4 and moderately or poorly differentiated HCCs (B, Figure 3). Significant copy number aberrations associated with grade 1 and well differentiated HCCs are gain of $11 \mathrm{q} 23.2$ containing ZBTB16 and gain of 16q23.2 containing $M A F$ (Table 4). Significant copy number aberrations associated with grade $2-4$ and moderately or poorly differentiated HCCs are gain of 1q21.1-q23.2 containing 261 genes including 5 cancer genes BCL9, ARNT, TPM3, $M U C 1$, and NTRK1 and gain of 8q11.1q13.1 containing 76 genes including 3 cancer genes TCEA1, PLAG1, and CHCHD7 (Table 4). In addition, gains of chromosomes 5 and $\mathrm{X}$ and loss of $9 \mathrm{p}$ were only found in grade $2-4$ and moderately or poorly differentiated HCCs although they did not reach statistical significance (Figure $3 \mathrm{~A}$ and $\mathrm{B}$ ).

Gene enrichment analysis on significant common aberrations identified by the comparison analysis I showed that the genes that are significantly enriched in grade 2-4 and moderately or poorly differentiated HCCs were involved in positive regulation of NF-kappaB transcription factor activity, including gains of S100A9, S100A12, S100A8, IL6R, NTRK1, AIM2, and NLRP3 on 1q, and in regulation of chemokine production, including gains of $D A R C$ on $1 \mathrm{q}$ and SNAI2 on 8q.

Furthermore, the numbers of chromosomal imbalance larger than $5 \mathrm{Mb}$ in each case ranged from 2 to 6 copy number changes per case (on average 3.8 copy number changes per case) for grade 1 and well differentiated tumors when compared with 3 to 12 copy number changes per case (on average 7.1 copy number changes per case) for grade $2-4$ or moderate or poorly differentiated tumors. The copy number variants (CNV) burden in terms of average number of CNVs for each category is significantly different with p-value of 0.023 using student's t-test.

In comparison analysis II, ten stage I HCCs (C, Figure 3) were compared with five stage II or III HCCs (D, Figure 3). Significant copy number aberrations associated with stage I tumors are gain of the long arm of chromosome 7 (7q), gain of $7 \mathrm{p} 11.2$ containing EGFR, and gain of $7 \mathrm{p} 21.2$ containing ETV1 (Table 5). Among the genes in the significantly enriched in stage I on chromosome $7 \mathrm{q}$ are genes involved in negative regulation of hydrogen peroxidemediated programmed cell death including HGF and $M E T$, and genes in androgen metabolic process including CYP3A4, AKR1D1, and SHH, and mismatch repair complex and single strand binding protein gene PMS2P5 and PMS2P1, MCM7 and SSBP1. In addition, loss of chromosome 17p containing gene TP53 was found in five of ten stage I HCCs, including three HCCs with whole arm deletion of 17p and two HCCs with deletions of most part of 17p (17p11.2-p13.2 of $18.5 \mathrm{Mb}$ and 17p11.2-pter of $18.3 \mathrm{Mb}$ respectively). However, this association did not reach statistical significance (Figure 4). TP53 deletion is commonly associated with poor prognosis in neoplasm; 
Table 2 Summary of regions of recurrent chromosome imbalance ( $>5 \mathrm{Mb}$ ), frequencies, and Sanger Census cancer genes in the region

\begin{tabular}{|c|c|c|c|c|c|c|c|}
\hline Region & $\begin{array}{l}\text { Region } \\
\text { length } \\
(\mathbf{k b})\end{array}$ & $\begin{array}{l}\text { Cytoband } \\
\text { location }\end{array}$ & $\begin{array}{l}\text { Copy } \\
\text { number }\end{array}$ & $\begin{array}{l}\text { Frequency } \\
(\%)\end{array}$ & $\begin{array}{l}\text { Number } \\
\text { of genes }\end{array}$ & $\begin{array}{l}\text { Number of } \\
\text { sanger census } \\
\text { cancer gene }\end{array}$ & Sanger census cancer gene \\
\hline chr1:732,712-24,356,209 & 23,624 & p36.33 - p36.11 & Loss & 20.00 & 375 & 7 & TNFRSF14, PRDM16, RPL22, CAMTA1, SDHB, PAX7, MDS2 \\
\hline chr1:143,582,356-249,250,621 & 105,668 & $\mathrm{q} 21.1-\mathrm{q} 44$ & Gain & 80.00 & 1155 & 17 & $\begin{array}{l}\text { PDE4DIP, BCL9, ARNT, TPM3, MUC1, PRCC, NTRK1, SDHC, } \\
\text { FCGR2B, PBX1, ABL2, TPR, MDM4, ELK4, SLC45A3, } \\
\text { H3F3A, FH }\end{array}$ \\
\hline chr4:80,505,114-115,297,840 & 34,793 & q21.21 - q26 & Loss & 33.33 & 167 & 2 & RAP1GDS1, TET2 \\
\hline chr5:0-46,279,735 & 46,280 & p15.33 - p11 & Gain & 33.33 & 181 & 2 & IL7R, LIFR \\
\hline chr5:49,584,189-180,704,505 & 131,120 & $q 11.1-q 35.3$ & Gain & 26.67 & 846 & 11 & $\begin{array}{l}\text { IL6ST, PIK3R1, APC, PDGFRB, CD74, ITK, EBF1, RANBP17, } \\
\text { TLX3, NPM1, NSD1 }\end{array}$ \\
\hline chr7:0-57,675,692 & 57,676 & $\mathrm{p} 22.3-\mathrm{p} 11.2$ & Gain & 33.33 & 381 & 10 & $\begin{array}{l}\text { CARD11, PMS2, ETV1, HNRNPA2B1, HOXA9, HOXA11, } \\
\text { HOXA13, JAZF1, IKZF1, EGFR }\end{array}$ \\
\hline chr7:61,750,617-159,138,663 & 97,388 & q11.21-q36.3 & Gain & 40.00 & 757 & 12 & $\begin{array}{l}\text { SBDS, ELN, HIP1, AKAP9, CDK6, MET, SMO, CREB3L2, } \\
\text { KIAA1549, BRAF, EZH2, MLL3 }\end{array}$ \\
\hline chr8:13,403,518-29,636,237 & 16,233 & p22 - p12 & Loss & 33.33 & 116 & 1 & PCM1 \\
\hline chr8:46,967,935-145,730,376 & 98,762 & $q 11.1-q 24.3$ & Gain & 60.00 & 501 & 13 & $\begin{array}{l}\text { CHCHD7, TCEA1, PLAG1, NCOA2, NBS1, HEY1, CBFA2T1, } \\
\text { UBR5, COX6C, EXT1, MYC, NDRG1, RECQL4 }\end{array}$ \\
\hline chr9:0-45,983,160 & 45,983 & p24.3 - p11.2 & Loss & 20.00 & 278 & 6 & JAK2, CD274, NFIB, MLLT3, FANCG, PAX5 \\
\hline chr17:3,728,554-12,900,807 & 9,172 & p13.2- p12 & Loss & 40.00 & 205 & 5 & USP6, TP53, PER1, GAS7, MAP2K5 \\
\hline chr17:13,297,102-18,590,696 & $5,293,594$ & $\mathrm{p} 12-\mathrm{p} 11.2$ & Loss & 33.33 & 77 & 0 & \\
\hline chrX:2,471,123-48,865,144 & 46,394 & p22.33 - p11.23 & Gain & 20.00 & 257 & 7 & ZRSR2, BCOR, KDM6A, SSX1, SSX4, WAS, GATA1 \\
\hline chrX:61,828,910-99,931,689 & 38,103 & $\mathrm{q} 11.1-\mathrm{q} 22.1$ & Gain & 26.67 & 156 & 4 & MSN, MED12, NONO, ATRX \\
\hline chrX:99,931,690-154,975,693 & 55,044 & $\mathrm{q} 22.1-\mathrm{q} 28$ & Gain & 33.33 & 613 & 5 & SEPT6, ELF4, GPC3, PHF6, MTCP1 \\
\hline
\end{tabular}


Table 3 Summary of statistically significant smaller copy number alterations ( $p$-value $<=0.05$ ) and genes in the region

\begin{tabular}{|c|c|c|c|c|c|c|c|c|}
\hline Region & $\begin{array}{l}\text { Region } \\
\text { length }(k b)\end{array}$ & $\begin{array}{l}\text { Cytoband } \\
\text { location }\end{array}$ & $\begin{array}{l}\text { Copy } \\
\text { number }\end{array}$ & $\begin{array}{l}\text { Frequency } \\
\text { (\%) }\end{array}$ & P-value & Genes & Gene symbols & $\begin{array}{l}\text { Sanger } \\
\text { census } \\
\text { cancer } \\
\text { gene }\end{array}$ \\
\hline chr1:142,898,654-143,481,059 & 582 & q21.1 & Loss & 26.67 & $<0.001$ & 0 & has-mir-3118-2, has-mir-3118-2 & \\
\hline chr2:127,807,016-127,821,014 & 14 & q14.3 & Loss & 20.00 & 0.021 & 1 & BIN1 & \\
\hline chr2:141,745,577-141,790,622 & 45 & q22.1 & Gain & 20.00 & 0.005 & 1 & LRP1B & \\
\hline chr2:236,033,001-236,677,413 & 644 & q37.2 & Gain & 20.00 & 0.005 & 1 & AGAP1 & \\
\hline chr3:196,726,226-196,756,289 & 30 & q29 & Loss & 20.00 & 0.002 & 2 & MFI2, MIF2-AS1 & \\
\hline chr4:1,792,487-1,809,740 & 17 & p16.3 & Loss & 33.33 & $<0.001$ & 1 & FGFR3 & FGFR3 \\
\hline chr4:69,305,095-69,412,970 & 108 & q13.2 & Gain & 40.00 & $<0.001$ & 2 & TMPRSS11E, UGT2B17 & \\
\hline chr7:13,933,308-14,336,685 & 403 & p21.2 & Gain & 46.67 & $<0.001$ & 1 & ETV1 & ETV1 \\
\hline chr7:38,306,193-38,380,749 & 75 & p14.1 & Loss & 33.33 & $<0.001$ & 1 & TARP & \\
\hline chr7:156,798,142-156,928,704 & 131 & q36.3 & Loss & 46.67 & $<0.001$ & 2 & MNX1, LOC645249 & \\
\hline chr8:145,737,034-145,741,006 & 4 & q24.3 & Loss & 40.00 & $<0.001$ & 1 & RECQL4 & RECQL4 \\
\hline chr9:139,390,677-139,425,667 & 35 & q34.3 & Loss & 26.67 & 0.003 & 1 & $\mathrm{NOTCH} 1$ & $\mathrm{NOTCH} 1$ \\
\hline chr10:3,514,976-3,988,938 & 474 & p15.2 - p15.1 & Gain & 26.67 & 0.008 & 1 & KLF6 & \\
\hline chr10:89,581,346-89,717,798 & 136 & q23.31 & Loss & 20.00 & 0.021 & 3 & CFL1P1, KLLN, PTEN & PTEN \\
\hline chr11:65,263,143-65,279,263 & 16 & q13.1 & Gain & 26.67 & 0.003 & 1 & MALAT1 & \\
\hline chr16:2,104,905-2,135,150 & 30 & p13.3 & Loss & 20.00 & 0.021 & 1 & $\mathrm{TSC} 2$ & TSC2 \\
\hline chr16:79,628,093-79,633,200 & 5 & $\mathrm{q} 23.2$ & Gain & 20.00 & 0.003 & 1 & MAF & MAF \\
\hline chr16:89,550,964-89,780,717 & 229753 & q24.3 & Gain & 20.00 & 0.003 & 12 & $\begin{array}{l}\text { ANKRD11, SPG7, SNORD68, RPL13, CPNE7, } \\
\text { DPEP1, CHMP1A, C16orf55, CDK10, } \\
\text { SPATA2L, VPS9D1, LOC100128881 }\end{array}$ & \\
\hline chr17:79,848,607-79,974,997 & 126390 & q25.3 & Loss & 26.67 & 0.02 & 11 & $\begin{array}{l}\text { ALYREF, ANAPC11, NPB, PCYT2, SIRT7, } \\
\text { MAFG, MAFG-AS1, PYCR1, MYADML2, } \\
\text { NOTUM, ASPSCR1 }\end{array}$ & ASPSCR1 \\
\hline chr18:14,827,524-15,293,288 & 465764 & p11.21 & Loss & 53.33 & $<0.001$ & 2 & ANKRD30B, MIR3156-2 & \\
\hline chr19:42,402,083-42,413,495 & 11412 & $q 13.2$ & Loss & 40.00 & $<0.001$ & 1 & ARHGEF1 & \\
\hline chrX:66,252,360-66,809,186 & 556827 & $q 12$ & Gain & 33.33 & $<0.001$ & 1 & AR & \\
\hline
\end{tabular}




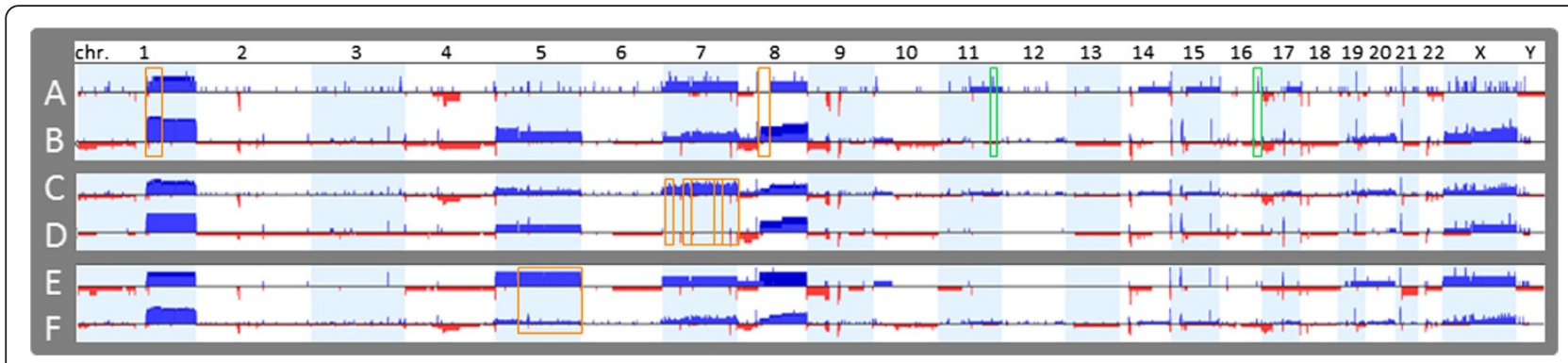

Figure 3 Frequency difference plot for gains and losses between groups in the comparison analysis. Comparison I: five of grade 1 and well differentiated HCCS (Figure 3A) vs ten of grade 2, 3 or 4 and moderately or poorly differentiated HCCs (Figure 3B). Comparison II: ten of Stage I HCC (Figure 3C) vs five of Stage II or III HCCs (Figure 3D). Comparison III: four of HCCs with vascular invasion (Figure 3E) vs eleven of HCCs without vascular invasion (Figure 3F). Regions of loss are indicated by red bars and regions of gains by blue bars.

however, the follow-up information is not available for most of the patients in this cohort.

In comparison analysis III, four HCCs with vascular invasion (E, Figure 3) were compared with eleven HCCs without vascular invasion (F, Figure 3). Significant copy number aberrations associated with HCCs with vascular invasion are gain of chromosome $5 q$ (Table 6). Among the genes in the significantly enriched in tumors with vascular invasion on $5 \mathrm{q}$ are genes involved in BMP signaling pathway including genes FST, ZFYVE16, RGMB, SMAD5, $E G R 1$, and NKX2-5 on chromosome $5 \mathrm{q}$, and genes involved in gamma-catenin binding including $F E R, A P C$, and CTNNA1 on chromosome 5q.

\section{Cluster analysis}

The dendrogram was generated based on recurrent chromosome aberrations of HCCs to construct genetic subgroups which reflected their genetic similarities in clusters (groups) (Figure 4). Chromosomal abnormalities partitioned well with HCCs which formed a clad (indicated by the arrow in Figure 4) with their paired nonneoplastic specimens at the base of the dendrogram. In the HCC clad, grade 1 and well differentiated HCCs were distributed as basal branches, while most of higher grade and less differentiated HCCs formed more organized clusters. Gain of 1q (80\%) was most common and found in all HCCs with grade 2-4 and three of 5 HCCs with grade 1 . The cluster of HCCs with gains of 1q, 8q, and trisomy 5 were associated with higher grades (2-4) and moderate to poor tumor differentiation, which were consistent with the results of comparison analysis (Tables 4, 5 and 6).

\section{Discussion}

In this study, our data demonstrated the feasibility of whole genome microarray analysis using FFPE samples of hepatocellular carcinoma, as all of specimens used in this study were FFPE samples, including HCCs and paired non-neoplastic cirrhotic liver tissues. Using FFPE specimens for molecular and genomic studies are technically challenging due to the chemical crosslinks and degradation of DNA and RNA in these samples. However, it is important to establish the methods for molecular characterization using genomic approaches with FFPE tissue samples as they make up a vast archive of pathologically well-characterized clinical samples and are an immense resource that can be used for conducting biomarker investigation.

Contrary to many previous copy number aberration studies of HCC using conventional CGH with 10$20 \mathrm{Mb}$ resolution or BAC array with 1-2 Mb resolution for genetic characterization of HCCs with various or unknown etiologies (Table 7) [9-14], this study focuses on $\mathrm{HCV}$ associated HCCs using high density whole genome oligo microarray analysis which provides higher resolution $(>2 \mathrm{~kb})$ to facilitate gene discovery. In addition, the levels of amplifications involving known oncogenic genes are readily detected. The copy number amplification can also be calculated based on the values of $\log _{2}$ ratio and tumor cellularity, as in specimen $\mathrm{HCCO} 1$ which had 7-copy amplification of MDM4 and PIK3C2B (Figure 1). MDM4 is known to contain a p53 binding domain at the $\mathrm{N}$-terminus and a RING finger domain at the C-terminus, and has been shown to interact with E2F1 [15], MDM2 [16,17] and P53 tumor suppressor protein [18], and overexpress in a variety of human cancers. PIK $3 C 2 B$ belongs to the phosphoinositide 3-kinase (PI3K) family which play certain roles in signaling pathways involved in cell proliferation, oncogenic transformation, cell survival, cell migration, and intracellular protein trafficking. Co-amplification of the adjacent genes may provide an additional growth advantage in HCC. In addition, PIK $3 C 2 B$ may serve as a potential therapeutic target. The protein encoded by PIK $3 C 2 B$ was demonstrated to play an essential role in $\mathrm{HCV}$ propagation in human HCC cells, and knockdown of PIK3C2B abolished HCV propagation in the cell [19].

Clonal chromosomal abnormalities were detected in all HCC samples but not found in their paired non-neoplastic tissues (Figure 4), demonstrating that 
Table 4 Result summary of the comparison analysis between grade 1/well differentiated HCCs and grade 2-4/moderately or poorly differentiated HCCs (Figure $3 A$ and $B$ )

\begin{tabular}{|c|c|c|c|c|c|c|c|c|}
\hline Region [hg19] & $\begin{array}{l}\text { Cytoband } \\
\text { location }\end{array}$ & $\begin{array}{l}\text { Copy } \\
\text { number }\end{array}$ & $\begin{array}{l}\text { Region } \\
\text { length (kb) }\end{array}$ & $\begin{array}{l}\text { Grade } 1 \text { and } \\
\text { well differentiated } \\
\text { HCC (freq. \%) }\end{array}$ & $\begin{array}{l}\text { Grade 2-4 } \\
\text { and moderately } \\
\text { and poorly } \\
\text { differentiated } \\
\text { HCC (freq. \%) }\end{array}$ & p-value & $\begin{array}{l}\text { Number } \\
\text { of genes }\end{array}$ & Sanger census cancer genes \\
\hline chr1:146,319,961-159,188,358 & q21.1- q23.2 & Gain & 12,868 & 40 & 100 & 0.022 & 261 & BCL9, ARNT, TPM3, MUC1, NTRK1 \\
\hline chr8:46,967,935-67,313,267 & q11.1 - q13.1 & Gain & 20,345 & 0 & 60 & 0.044 & 76 & CHCHD7, TCEA1, PLAG1 \\
\hline chr11:113,937,346-114,144,024 & q23.2 & Gain & 207 & 60 & 0 & 0.022 & 1 (ZBTB16) & \\
\hline chr16:79,628,093-79,633,200 & q23.2 & Gain & 5 & 60 & 0 & 0.022 & 1 & MAF \\
\hline
\end{tabular}


Table 5 Result summary of the comparison analysis between Stage I HCC and Stage II or III HCCs (Figure 3C and D)

\begin{tabular}{|c|c|c|c|c|c|c|c|c|}
\hline Region [hg19] & $\begin{array}{l}\text { Cytoband } \\
\text { location }\end{array}$ & $\begin{array}{l}\text { Copy } \\
\text { number }\end{array}$ & $\begin{array}{l}\text { Region } \\
\text { length (kb) }\end{array}$ & $\begin{array}{l}\text { Stage I } \\
\text { (freq. \%) }\end{array}$ & $\begin{array}{l}\text { Stages II-III } \\
\text { (freq. \%) }\end{array}$ & $\mathrm{p}$-value & $\begin{array}{l}\text { Number } \\
\text { of genes }\end{array}$ & Sanger census cancer genes \\
\hline chr7:13,933,308-14,289,034 & p21.2 & Gain & 356 & 70 & 0 & 0.026 & 2 & ETV1 \\
\hline chr7:54,910,410-55,228,621 & p11.2 & Gain & 318 & 70 & 0 & 0.026 & 1 & EGFR \\
\hline chr7:61,750,617-159,138,663 & q11.21-q36.3 & Gain & 97,388 & 60 & 0 & 0.044 & 757 & $\begin{array}{l}\text { SBDS, ELN, HIP1, AKAP9, CDK6, MET, SMO, } \\
\text { CREB3L2, KIAA1549, BRAF, EZH2, MLL3 }\end{array}$ \\
\hline chr7:115,832,560-116,493,846 & q31.2 & Gain & 661 & 70 & 0 & 0.026 & 4 & MET \\
\hline
\end{tabular}


Table 6 Result summary of the comparison analyses between HCCs with vascular invasion and without vascular invasion (Figure 3E and F)

\begin{tabular}{|c|c|c|c|c|c|c|c|c|}
\hline Region [hg19] & Cytoband location & $\begin{array}{l}\text { Copy } \\
\text { number }\end{array}$ & $\begin{array}{l}\text { Region } \\
\text { length }(k b)\end{array}$ & $\begin{array}{l}\text { Vascular } \\
\text { invasion } \\
\text { (freq. \%) }\end{array}$ & $\begin{array}{l}\text { No vascular } \\
\text { invasion } \\
\text { (freq. \%) }\end{array}$ & $\mathrm{p}$-value & $\begin{array}{l}\text { Number } \\
\text { of genes }\end{array}$ & Sanger census cancer genes \\
\hline chr5:49,584,189-180,704,505 & $q 11.1-q 35.3$ & Gain & 131,120 & 75 & 9.091 & 0.033 & 846 & $\begin{array}{l}\text { IL6ST, PIK3R1, APC, PDGFRB, CD74, ITK, } \\
\text { EBF1, RANBP17, TLX3, NPM1, NSD1 }\end{array}$ \\
\hline
\end{tabular}




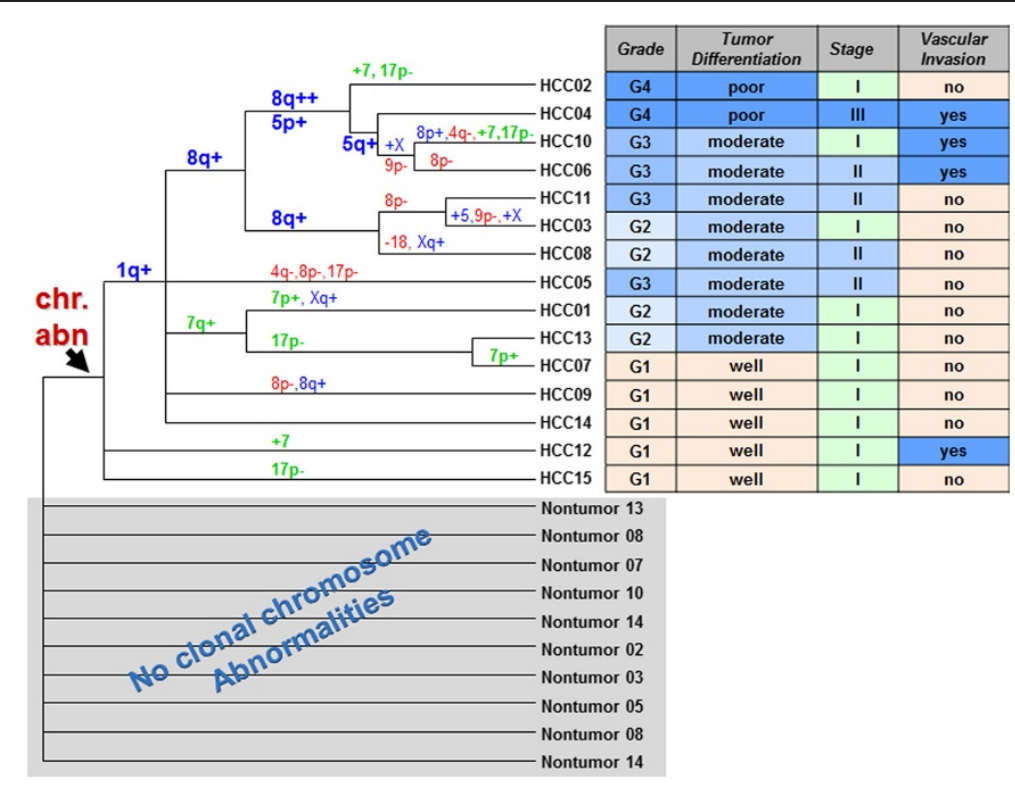

Figure 4 The dendrogram generated from cluster analysis. Genetic subgroups shown as clads/clusters were labeled with shared chromosomal aberrations on the branches leading to the clades or the HCC specimen. Chromosomal abnormalities partitioned with HCCs and formed a clad that was indicated by the arrow. Their paired non-neoplastic specimens were at the base of the dendrogram without clonal chromosomal aberrations detected. Clinical and pathological features associated with each HCC were listed in the table next to it.

chromosomal copy number aberrations detected by whole genome microarray analysis were tumor-associated somatic changes and may serve as good genetic markers to distinguish tumors from non-neoplastic cirrhotic nodules.

The frequent chromosomal aberrations $(>5 \mathrm{Mb})$ found in this study, including gains of $1 \mathrm{q}$ and $8 \mathrm{q}$ and loss of $1 \mathrm{p}, 4 \mathrm{q}, 8 \mathrm{p}, 9 \mathrm{p}$, and $17 \mathrm{p}$, were largely consistent with previous reports for HCCs with various etiologies, including virus-associated and non-viral HCCs (Table 7) [9-14]. Similar pattern of chromosomal imbalances with different etiology suggests a common basic state for HCC development, most likely the chronic process of cirrhosis due to non-specific inflammatory and regenerative processes. However, frequent gains of chromosomes 5 (33\%) and/or 7 (33-40\%) found in this cohort (Table 2, Figures 2 and 4) have not been reported previously as common chromosomal aberrations in HCC (Table 7), suggesting that trisomy 5 and/or trisomy 7 could be the specific aberrations for $\mathrm{HCV}$ associated $\mathrm{HCCs}$ and future studies are warranted.

In addition, smaller deletions $(3.9-582 \mathrm{~kb})$ were identified to be statistically significant in this HCVHCC cohort. These deletions contained known cancer genes based on the Sanger Census cancer gene list, including FGFR3, RECQL4, NOTCH1, PTEN, TSC2, and/ or ASPSCR1 (Table 3) which suggested their roles as tumor suppressor genes in the development of HCC. These genetic alterations were undetected by previous studies with conventional CGH and BAC arrays, most likely due to the low resolution of the analyses.

Table 7 Comparison of frequencies of major gains and losses of genomic regions from this study and previous reports

\begin{tabular}{|c|c|c|c|c|c|c|c|c|c|c|c|c|c|c|c|c|}
\hline \multirow{2}{*}{ Method } & \multirow{2}{*}{ Etiology } & \multicolumn{8}{|c|}{ Chromosomal gain (frequency, \%) } & \multicolumn{6}{|c|}{ Chromosomal loss (frequency, \%) } & \multirow{2}{*}{ References } \\
\hline & & $1 q$ & $5 p$ & $5 q$ & $7 p$ & $7 q$ & $8 q$ & $17 q$ & $20 q$ & $1 p$ & $4 q$ & $6 q$ & $8 p$ & $9 p$ & $17 p$ & \\
\hline Conventional CGH & $\mathrm{HCV}, \mathrm{HBV}$, or non-viral & 46 & 27 & $<5$ & $<5$ & $<5$ & 69 & 46 & 31 & 35 & 42 & 15 & 58 & 27 & 31 & {$[12]$} \\
\hline BAC or Oligo CGH & $\mathrm{HCV}, \mathrm{HBV}$, or non-viral & $>25$ & $N A^{*}$ & NA & NA & NA & $>25$ & $>25$ & NA & NA & $>25$ & $>25$ & $>25$ & $>25$ & $>25$ & [11] \\
\hline Conventional CGH & $\mathrm{HCV}, \mathrm{HBV}$, or non-viral & 49 & $<5$ & 6 & 13 & 15 & 55 & 13 & 12 & 18 & 33 & 33 & 55 & 13 & 22 & [13] \\
\hline Conventional CGH & HCV or HBV & 46 & $<5$ & $<5$ & $<5$ & $<5$ & 41 & 37 & $<5$ & 24 & 39 & 61 & 44 & 24 & $<5$ & [14] \\
\hline Conventional CGH & HCV only & 46 & 5 & 5 & 9 & 9 & 31 & 43 & 27 & 37 & 48 & 23 & 28 & 9 & 37 & [10] \\
\hline Conventional CGH & HCV only & 79 & 16 & 11 & 16 & 11 & 37 & 16 & 11 & 32 & 53 & 21 & 32 & 11 & 79 & [9] \\
\hline oligo CGH & HCV only & 80 & 33 & 27 & 33 & 40 & 60 & $<5$ & $<5$ & 20 & 33 & 7 & 33 & 20 & 40 & This study \\
\hline
\end{tabular}

*NA - note available. 
FGFR3 appears to have dual actions in cancers. FGFR3 can have both tumor suppressive and oncogenic properties. It was shown that FGFR3 signal can limit tumor growth with epithelial origin. Therefore, for tumors of epithelial origin, loss of FGFR3 was found in higher grade tumor while activating mutations of FGFR3 were found in benign or low grade tumor with good prognosis [20]. Although little is known on FGFR3 actions in HCC, FGFR3 deletion was found mostly in grade 2-3 $\mathrm{HCC}$ in this cohort, indicating FGFR3 as a tumor suppressor gene in HCC and is associated with HCC of higher grade. FGFR3 oncogenic property is crucial for targeted therapy involving specific tyrosine kinase inhibitors. Loss of NOTCH1 resulted in a continuous proliferation of hepatocytes and nodular regenerative hyperplasia in conditional NOTCH1 knockout mouse model [21]. PTEN as a tumor suppressor, negatively regulating AKT/ PKB signaling pathway by preferentially dephosphorylates phosphoinositide substrates, is mutated in a large number of cancers including 40-50\% of human liver cancers such as HCC and cholangiocarcinoma [22]. TSC2 is a tumor suppressor and is able to stimulate specific GTPases. Loss of TSC2 leads to activation of MTOR and downstream signaling elements, causes endoplasmic reticulum (ER) stress, activates the unfolded protein response, and results in tumor development [23]. TSC2 deletions were found in $\mathrm{HCV}$-associated HCC with grade 2-3 and moderate differentiation and without vascular invasion in this cohort. This finding is consistent with the finding that decreased TSC2 expression was found to be significantly correlated with higher grade and poor prognosis, but is inconsistent with the association with vascular invasion in a recent study [24]. The discrepancy may be explained by the population difference as all HCC cases are soly HCV associated in this study while the majority cases in Huang's study were HBV associated HCCs with only two HCVassociated HCCs [24]. RECQL4, a DNA helicase that belongs to the RecQ helicase family, has not been previously recognized to be involved in HCC development. This study also showed that deletions involving whole gene ASPSCR1 (alveolar soft part sarcoma chromosome region, candidate 1) were detected in $\mathrm{HCC}$ with statistical significance. The deletions of ASPSCR 1 most likely resulted in the loss of function and decreased expression of ASPSCR1, suggesting its role as a potential tumor suppressor gene in the development of HCC. In addition, loss of function and decreased expression of ASPSCR1 has also been implicated in synthetic lethal interactions in cancer [25]. Gene ASPSCR1 is relatively uncharacterized. An ASPSCR1-TFE3 fusion protein due to an unbalanced translocation $\operatorname{der}(17) \mathrm{t}(\mathrm{X} ; 17)$ has been associated with alveolar soft-part sarcoma (ASPS), which resulted in unregulated transcription of TFE3 and TFE3-regulated genes and a truncated allele of
ASPSCR1 with loss of function [26]. Future studies of the role of ASPSCR1 in HCC are warranted.

There is great interest in identifying genetic markers of HCC that qualify for risk stratification. Most previous studies did not have detailed pathological data and correlation analysis between the genetics data and pathological data have not been conducted. We found several correlations between genetic data and clinicopathological data by comparison analysis. Gain of 1q21.1-q23.2 and gain of 8q11.1q13.1 were significantly associated with grade 2-4 and moderately or poorly differentiated HCCs (Table 4), including genes that are significantly enriched in positive regulation of nuclear factor-kappa B (NF-kappaB) transcription factor activity and regulation of chemokine production. This result suggests that NF- kappaB plays a role in the progression of $\mathrm{HCC}$. The NF- $\mathrm{KB}$ transcription factor family is known to play an important role in many immune and inflammatory responses, and inflammation is considered a hallmark of cancer [27]. Enhanced expression of inflammatory cytokines and chemokines as key coordinators of the cross talk between hepatocytes and activated hepatic stellate cells was shown to be crucial in HCC development and progression, either by direct signaling or by recruiting immune cells $[27,28]$.

Comparison analysis also showed that gain of chromosome $5 \mathrm{q}$ was significantly associated with HCCs with vascular invasion (Table 6), which is a poor prognostic indicator for tumor spread. Gene enrichment analysis detected genes in bone morphogenetic proteins (BMP) signaling pathway including genes FST, ZFYVE16, RGMB, SMAD5, EGR1, and NKX2-5 on chromosome 5q and in gamma-catenin binding including $F E R, A P C$, and CTNNA1 on chromosome 5q (Table 6), suggesting that copy number gain and increased expression of BMP signaling may contribute to tumor progression and invasion. BMPs comprising the largest family within the TGF- $\beta$ superfamily, originally reported as factors that induce bone and cartilage formation and development, have been shown to be critical for cancer development and progression [29]. Elevated expression levels of BMPs have been detected in many types of solid tumors, and BMP signaling pathway are intimately involved in both the inhibition and promotion of cancer progression [30]. A similar dual role for the superfamily member TGF $\beta$ is known to act as a tumor suppressor during the initial steps of tumorigenesis, but later found to promote tumor progression and invasion [31].

Furthermore, copy number variant $(\mathrm{CNV})$ burden in terms of number of observed acquired CNV events $(>5 \mathrm{Mb})$ in each case was greater in HCCs with grade $2-4$ or moderate or poorly differentiated tumors (average 7.1 CNVs per case) compared to HCCs with grade 1 and well differentiated tumors (average $3.8 \mathrm{CNVs}$ per 
case), indicating higher genomic instability in more advanced HCCs.

HCC has gender disparity with an increased frequency in males. Copy gain involving androgen receptor $(A R)$ were observed in five HCCs of male patients in this cohort, including gain of Xq in four HCCs, and a gain containing only gene $A R$ in one HCC. In addition, a gain containing the promoter region and first two exons of $A R$ was observed in one HCC. It has been proposed that higher activity of androgen pathway functions as a tumor-promoting factor in male hepatocarcinogenesis, as knockout of $A R$ expression in hepatocytes delayed the development of N',N'-diethylnitrosamine (DEN)-induced HCC [32].

\section{Conclusions}

This study has provided a detailed map of genomic aberrations occurring in $\mathrm{HCV}$-associated $\mathrm{HCC}$ and has suggested candidate genes. As many frequent gains and losses are also common in HCCs with various etiologies, gains of chromosomes 5 and/or 7 appeared to be the specific aberrations for $\mathrm{HCV}$-associated HCCs. While gain of 1q21.1-q23.2 and gain of 8q11.1q13.1 are significantly associated with grade $2-4$ and moderately or poorly differentiated HCCs, gain of chromosome $7 \mathrm{q}$ is significantly associated with stage I HCCs, and gain of chromosome $5 q$ was significantly associated with HCCs with vascular invasion which is poor prognosis indicator for tumor spreading. NF- kappaB and BMP signaling pathways were indicated for HCC development and progression. This study demonstrated that genomic microarray test can be used to distinguish HCC from nonneoplastic cirrhotic nodules and to identify signaling pathways involved in HCC development and prognostic factors associated with HCC progression using pathologically characterized FFPE samples. Our data support the utility of genomic microarray test for the diagnosis, risk stratification, and pathogenic studies of HCC.

\section{Methods}

\section{FFPE tissue specimens}

The pathological archives of representative number of hepatocellular carcinoma (HCC) were retrospectively reviewed and selected from the Department of Pathology at the University of Washington Medical center, including $15 \mathrm{HCV}$-associated HCC in cirrhotic livers, all from explanted liver specimens. The study protocol was reviewed and approved by the institutional review boards (University of Washington, Human Subjects Division). All specimens used in this study were formalin-fixed paraffinembedded (FFPE) tissue specimens. Hematoxylin and eosin stained slides were reviewed to confirm the diagnosis and to grade and subclassify the HCC accordingly [33]. In addition, both cancer tissues and nearby cirrhotic non-neoplastic tissues were processed for the genetic characterization for 10 of $15 \mathrm{HCV}$-associated $\mathrm{HCC}$ cases, while in five of 15 cases, only HCC tissues were available for analysis.

We reviewed the clinical records of these patients and retrieved the data on demographic characteristics and clinical outcomes (Table 1). The tumor-node-metastasis (TNM) staging system of American Joint Committee on Cancer (Edition 7) was used to determine the T stage of the tumors [34].

\section{DNA extraction}

Tumor and non-neoplastic areas were identified in $\mathrm{H}$ \& E-stained slides and corresponding areas were dissected with a scalpel from the paraffin slides. Genomic DNA from FFPE tissue was extracted using manufacture recommended procedure (Agilent Technologies, Santa Clara, CA, USA) which is based on the method described by van Beers et al. [35] using the Qiagen DNeasy Blood \& Tissue Kit (Qiagen Inc, Valencia, CA, USA). This procedure is optimized for 5 sections of $4-5$ micron FFPE section containing about $1 \mathrm{~cm}^{2}$ of tissue. The concentration and the quality of genomic DNA were determined using Spectrophotometer NanoDrop ND-1000 (Thermo Fisher Scientific Inc., Wilmington, DE, USA).

\section{Genomic microarray analysis}

Purified genomic DNA and the normal control reference DNA were then digested with restriction enzymes, labeled separately with contrasting fluorescence, and competitively hybridized to the custom designed high density oligonucleotide microarray as specified by the manufacturer (Agilent Technologies, Santa Clara, CA, USA). Chromosomal microarray analysis was performed on genomic DNA using the Agilent SurePrint G3 Cancer CGH + SNP 4x180K Array, a cancer-specific $\mathrm{CGH}+\mathrm{SNP}$ microarray designed by Cancer Genomics Consortium (CGC) (http://www.chem-agilent.com/pdf/ 5990-9183en_lo_CGH+SNP_Cancer.pdf). Arrays were scanned using a DNA Microarray Scanner with SureScan High-Resolution technology (Agilent Technologies, Santa Clara, CA, USA). Whole genome microarray data were analyzed using Agilent CytoGenomics 2.5 to identify copy number changes. The global ADM2 algorithm with a threshold 6.0 and aberration filter for a minimum of five probes per region were applied. The CGH array data were also evaluated independently with second software Nexus Copy Number 7.5 (BioDiscovery, Inc. Hawthorne, CA, USA) to confirm the copy number changes identified by Cytogenomics. The $\log 2 \mathrm{R}$ ratios provide information regarding copy number. These were determined by visual inspection. Genomic linear positions were given relative to NCBI build 37 (hg19, 
http://genome.ucsc.edu/). Analysis was limited to detect copy number changes that include at least 5 probes (markers) for deletions or duplications.

\section{Statistical analysis}

To identify nonrandom gains and losses across multiple samples that are more likely to drive cancer pathogenesis, genetic aberrations in this cohort were evaluated for their statistically significance using statistical approaches with STAC algorithm adopted in Nexus 7.5 (BioDiscovery, Inc. Hawthorne, CA, USA). Significance Testing for Aberrant Copy number (STAC) is a method for testing the significance of DNA copy number aberrations across multiple microarray experiments to identify a set of aberrations that are aggregate in the overlapping regions such that it would not occur randomly [36]. The method applies two statistics, the frequency of aberration at a location across the entire sample set and pvalue assigned to each location on the genome by using a multiple testing corrected permutation approach. The p-Value cut-off of 0.05 and the Aggregate \% cut-off of $20 \%$ were used in the analyses.

Comparison analysis was conducted to correlate recurrent genetic alterations observed with clinical and pathologic data using Nexus 7.5 (BioDiscovery, Inc. Hawthorne, CA, USA). Statistical comparison using Fisher Exact test was performed to determine the $\mathrm{p}$-value of certain genetic aberration in one group vs the other group in comparison. Scores exceeding the significant threshold with p-Value cut-off of 0.05 and below the differential threshold cut-off of $25 \%$ were used in the analyses. Comparisons between different groups of tumors based on the pathologic features were conducted to detect genomic regions that were significant different between the groups in a comparison based on the p-value. The factor sets compared in this study included tumor grade and differentiation, tumor stage, and vascular invasion.

Using significant common aberrations identified by comparison analysis, gene enrichment analysis on these selected regions of interest was conducted to attain the biological implications of these aberrations using Nexus 7.5 (BioDiscovery, Inc. Hawthorne, CA, USA). Enrichment analysis identifies gene ontology (GO) terms that are significantly overrepresented and identifies the genes annotated with these terms within this aberrant region $[37,38]$.

\section{Clustering analysis}

The genetic similarity between the tumor samples were evaluated using parsimony analyses by clustering similar recurrent aberration of genetic data using PAUP, version 3.1.1 $[39,40]$ to generate a dendrogram that illustrated the arrangement of the clusters. The identified clusters with recurrent genetic aberrations were correlated with clinical and pathological features.

\section{Competing interests}

The authors declare that they have no competing interests.

\section{Authors' contributions}

YJL contributed to the conception and design of the study, performed microarray data analysis and interpretation, performed the statistical analysis, wrote and revised the manuscript. YZ carried out genomic microarray analysis. MMY obtained the specimens and provided the pathology diagnosis, and participated in the study design and involved in revising the manuscript. All authors read and approved the final manuscript.

\section{Authors' information}

Yajuan J. Liu PhD FACMG

Board certified in Clinical Cytogenetics and Clinical Molecular Genetics.

Co-Director of Cytogenetics and Genomics Laboratory

University of Washington Medical Center

Assistant Professor

Department of Pathology, University of Washington School of Medicine, Seattle, WA, USA

Yang Zhou MS

Technologist

Cytogenetics and Genomics Laboratory. University of Washington Medical Center.

Matthew M. Yeh, MD, PhD

Board certified in Anatomic and Clinical Pathology

Director, Gastrointestinal and Hepatic Pathology Fellowship Program. Professor

Department of Pathology, University of Washington School of Medicine, Seattle, WA, USA.

Received: 16 July 2014 Accepted: 26 October 2014

Published online: 25 November 2014

\section{References}

1. Munoz N, Bosch X: Epidemiology of Hepatocellular Carcinoma. In Neoplasms of the Liver. Edited by Okuda K, Ishak KG. Tokyo: Springer; 1989:3.

2. Bosch F, Munoz N: Hepatocellular Carcinoma in the World: Epidemiologic Questions. In Etiology, Pathology and Treatment of Hepatocellular Carcinoma in America, Advances in Applied Technology Series. Edited by Tabor E, DiBisceglie AM, Purcell RH. Gulf, Houston; 1991:35.

3. Hashem BE-S: Hepatocellular carcinoma: recent trends in the United States. Gastroenterology 2004, 127:S27-S34.

4. Fattovich G, Stroffolini T, Zagni I, Donato F: Hepatocellular carcinoma in cirrhosis: incidence and risk factors. Gastroenterology 2004, 127:S35-S50.

5. Bralet MP, Regimbeau JM, Pineau P, Dubois S, Loas G, Degos F, Bralet MP, Regimbeau JM, Pineau P, Dubois S, Loas G, Degos F: Hepatocellular carcinoma occurring in nonfibrotic liver: epidemiologic and histopathologic analysis of 80 French cases. Hepatology 2000, 32:200-204.

6. Niederau C, Lange S, Heintges T: Prognosis of chronic hepatitis C: results of a large, prospective cohort study. Hepatology 1998, 28:1687-1695.

7. Bruix J, Sherman M: Management of hepatocellular carcinoma. Hepatology 2005, 42:1208-1236.

8. Villanueva A, Newell P, Chiang DY, Friedman SL, Llovet JM: Genomics and signaling pathways in hepatocellular carcinoma. Semin Liver Dis 2007, 27:055,076.

9. Hashimoto K, Mori N, Tamesa T, Okada T, Kawauchi S, Oga A, Furuya T, Tangoku A, Oka M, Sasaki K: Analysis of DNA copy number aberrations in hepatitis $C$ virus-associated hepatocellular carcinomas by conventional CGH and array CGH. Mod Pathol 2004, 17:617-622.

10. Sakakura C, Hagiwara A, Taniguchi H, Yamaguchi T, Yamagishi H, Takahashi T, Koyama K, Nakamura Y, Abe T, Inazawa J: Chromosomal aberrations in human hepatocellular carcinomas associated with hepatitis $C$ virus infection detected by comparative genomic hybridization. $\mathrm{Br} J$ Cancer 1999, 80:2034-2039.

11. Guo X, Yanna, Ma X, An J, Shang Y, Huang Q, Yang H, Chen Z, Xing J: A meta-analysis of array-CGH studies implicates antiviral immunity pathways in the development of hepatocellular carcinoma. PLOS One 2011, 6:e28404. 
12. Zondervan PE, Wink J, Alers JC JNIJ, Schalm SW, de Man RA, van Dekken H: Molecular cytogenetic evaluation of virus-associated and non-viral hepatocellular carcinoma: analysis of 26 carcinomas and 12 concurrent dysplasias. J Pathol 2000, 192:207-215.

13. Homayounfar K, Schwarz A, Enders C, Cameron S, Baumhoer D, Ramadori G, Lorf T, Gunawan B, Sander B: Etiologic influence on chromosomal aberrations in European hepatocellular carcinoma identified by $\mathrm{CGH}$. Pathol Res Pract 2013, 209:380-387.

14. Tornillo L, Carafa V, Richter J, Sauter G, Moch H, Minola E, Gambacorta M, Bianchi L, Vecchione R, Terracciano LM: Marked genetic similarities between hepatitis $B$ virus-positive and hepatitis $C$ virus-positive hepatocellular carcinomas. J Pathol 2000, 192:307-312.

15. Strachan GD, Jordan-Sciutto KL, Rallapalli R, Tuan RS, Hall DJ: The E2F-1 transcription factor is negatively regulated by its interaction with the MDMX protein. J Cell Biochem 2003, 88:557-568.

16. Kadakia M, Brown TL, McGorry MM, Berberich SJ: MdmX inhibits Smad transactivation. Oncogene 2002, 21:8776-8785.

17. Tanimura S, Ohtsuka S, Mitsui K, Shirouzu K, Yoshimura A, Ohtsubo M: MDM2 interacts with MDMX through their RING finger domains. FEBS Lett 1999, 447:5-9.

18. Badciong JC, Haas AL: MdmX is a RING finger ubiquitin ligase capable of synergistically enhancing Mdm2 ubiquitination. J Biol Chem 2002, 277:49668-49675.

19. Maehama T, Fukasawa M, Date T, Wakita T, Hanada K: A class II phosphoinositide 3-kinase plays an indispensable role in hepatitis $C$ virus replication. Biochem Biophys Res Commun 2013, 440:150-156.

20. Lafitte M, Moranvillier I, Garcia S, Peuchant E, lovanna J, Rousseau B, Dubus P, Guyonnet-Duperat V, Belleannee G, Ramos J, Bedel A, de Verneuil H, Moreau-Gaudry F, Dabernat S: FGFR3 has tumor suppressor properties in cells with epithelial phenotype. Mol Cancer 2013, 12:83.

21. Croquelois A, Blindenbacher A, Terracciano L, Wang X, Langer I, Radtke F, Heim $\mathrm{MH}$ : Inducible inactivation of Notch1 causes nodular regenerative hyperplasia in mice. Hepatology 2005, 41:487-496.

22. Chen WT, Zhu G, Pfaffenbach K, Kanel G, Stiles B, Lee AS: GRP78 as a regulator of liver steatosis and cancer progression mediated by loss of the tumor suppressor PTEN. Oncogene 2013, doi:10.1038/onc.2013.1437.

23. Ozcan U, Ozcan L, Yilmaz E, Duvel K, Sahin M, Manning BD, Hotamisligil GS Loss of the tuberous sclerosis complex tumor suppressors triggers the unfolded protein response to regulate insulin signaling and apoptosis. Mol Cell 2008, 29:541-551.

24. Huang KT, Huang YH, Li P, He B, Chen ZK, Yu X, Chen JO, Zhang QY, Shi $H Q$, Shan YF: The correlation between TSC2 and GSK3beta levels, and outcomes of patients with hepatocellular carcinoma treated by hepatectomy. Hepatol Res 2013. doi:10.1111/hepr.12256.

25. Deshpande R, Asiedu MK, Klebig M, Sutor S, Kuzmin E, Nelson J, Piotrowski J, Shin SH, Yoshida M, Costanzo M, Boone C, Wigle DA, Myers CL: A comparative genomic approach for identifying synthetic lethal interactions in human cancer. Cancer Res 2013, 73:6128-6136.

26. Folpe AL, Deyrup AT: Alveolar soft-part sarcoma: a review and update. J Clin Pathol 2006, 59:1127-1132.

27. Hanahan D, Weinberg RA: Hallmarks of cancer: the next generation. Cell 2011, 144:646-674

28. Coulouarn C, Corlu A, Glaise D, Guenon I, Thorgeirsson SS, Clement B: Hepatocyte-stellate cell cross-talk in the liver engenders a permissive inflammatory microenvironment that drives progression in hepatocellular carcinoma. Cancer Res 2012, 72:2533-2542.

29. Lee JH, Lee GT, Woo SH, Ha YS, Kwon SJ, Kim WJ, Kim IY: BMP-6 in renal cell carcinoma promotes tumor proliferation through IL-10-dependent M2 polarization of tumor-associated macrophages. Cancer Res 2013, 73:3604-3614

30. Kallioniemi A: Bone morphogenetic protein 4-a fascinating regulator of cancer cell behavior. Cancer Genet 2012, 205:267-277.

31. Derynck R, Akhurst RJ, Balmain A: TGF-beta signaling in tumor suppression and cancer progression. Nat Genet 2001, 29:117-129.

32. Yeh $\mathrm{SH}, \mathrm{Chen} \mathrm{PJ:} \mathrm{Gender} \mathrm{disparity} \mathrm{of} \mathrm{hepatocellular} \mathrm{carcinoma:} \mathrm{the} \mathrm{roles}$ of sex hormones. Oncology 2010, 78(Suppl 1):172-179.

33. Kojiro M: Chapter 4, Morphologic evolution of hepatocellular carcinoma: from early to advanced. In Pathology of Hepatocellular Carcinoma Kojiro. Edited by Wiley-Blackwell; 2006:51-62.

34. Edge SBBD, Compton CC, Fritz AG, Greene FL, Trotti A (Eds): AJCC Cancer Staging Manual. 7th edition. New York, NY: Springer; 2010:237-246.
35. van Beers EH, Joosse SA, Ligtenberg MJ, Fles R, Hogervorst FB, Verhoef $\mathrm{S}$, Nederlof PM: A multiplex PCR predictor for aCGH success of FFPE samples. Br J Cancer 2006, 94:333-337.

36. Diskin SJ, Eck T, Greshock J, Mosse YP, Naylor T, Stoeckert CJ Jr, Weber BL, Maris JM, Grant GR: STAC: A method for testing the significance of DNA copy number aberrations across multiple array-CGH experiments. Genome Res 2006, 16:1149-1158.

37. Subramanian A, Tamayo P, Mootha VK, Mukherjee S, Ebert BL, Gillette MA, Paulovich A, Pomeroy SL, Golub TR, Lander ES, Mesirov JP: Gene set enrichment analysis: a knowledge-based approach for interpreting genome-wide expression profiles. Proc Natl Acad Sci U S A 2005, 102:15545-15550.

38. Mootha VK, Lindgren CM, Eriksson KF, Subramanian A, Sihag S, Lehar J, Puigserver P, Carlsson E, Ridderstrale M, Laurila E, Houstis N, Daly MJ, Patterson N, Mesirov JP, Golub TR, Tamayo P, Spiegelman B, Lander ES, Hirschhorn JN, Altshuler D, Groop LC: PGC-1alpha-responsive genes involved in oxidative phosphorylation are coordinately downregulated in human diabetes. Nat Genet 2003, 34:267-273.

39. Swofford D: PAUP: Phylogenetic Analysis Using Parsimony. Version 3.1.1. Washington, DC: National Museum of Natural History; 1993.

40. Liu YJ, Hall BD: Body plan evolution of ascomycetes, as inferred from an RNA polymerase II phylogeny. Proc Natl Acad Sci U S A 2004, 101:4507-4512.

doi:10.1186/s13039-014-0081-8

Cite this article as: Liu et al:: Recurrent genetic alterations in hepatitis C-associated hepatocellular carcinoma detected by genomic microarray: a genetic, clinical and pathological correlation study. Molecular Cytogenetics 2014 7:81.

\section{Submit your next manuscript to BioMed Central and take full advantage of:}

- Convenient online submission

- Thorough peer review

- No space constraints or color figure charges

- Immediate publication on acceptance

- Inclusion in PubMed, CAS, Scopus and Google Scholar

- Research which is freely available for redistribution

Submit your manuscript at www.biomedcentral.com/submit
C) Biomed Central 